\title{
STABILITY OF MOTION-PICTURE FILMS AS DETERMINED BY ACCELERATED AGING ${ }^{1}$
}

\author{
By John R. Hill ${ }^{2}$ and Charles G. Weber
}

\section{FOREWORD *}

For some time past, many institutions-libraries in particular-have faced the problem of record storage in terms of space, cost, and stability. Among other subjects seriously considered with a view to a solution is the problem of photographically transferring records to a film base by what is commonly known as microphotography.

Custodians of records have accumulated experience in this field, but most of them hesitate to adopt a definite policy until more is known about the stability of film bases. The National Archives is especially interested owing to the great volume of Government records under its jurisdiction, duplicates of which in many cases are not available. This interest was increased when the Division of Motion Pictures and Sound Recordings was set up and efforts were made to preserve such material.

As a result of this interest the National Archives transferred money and personnel to the National Bureau of Standards with the understanding that the study then in progress on cellulose acetate film would be broadened to cover also cellulose nitrate film. Under this arrangement the work has moved forward rapidly and with gratifying results. The National Archives acknowledges the cooperation of the National Bureau of Standards and other participants in this work for their helpful contributions insofar as it has been a beneficiary.

\section{CONTENTS}

8 871

II. Motion-picture films studied

III. Description of tests

IV. Physical properties... 873

1. Folding endurance 873

2. Loss in weight

V. Chemical properties

1. Acidity $(\mathrm{pH})$

2. Stability test of nitrate film

3. Copper number 877

4. Viscosity

5. Effects of aging on gelatin emulsion 880

VI. Summary _....... 880

\section{INTRODUCTION}

Motion-picture films on a cellulose acetate base are being used as an inexpensive and convenient means of reproducing important records and for making original records for historical and other edu-

1 This study was made with the assistance of a fund granted by the Carnegie Corporation to the National Research Council and a fund allotted by the National Archives, and with the advice of the following committee appointed by the National Research Council: Robert C. Binkley, American Council of Learned Societies and Social Science Research Council; John G. Bradley, National Archives; E. K. Carver, Eastman Kodak Company; H. T. Cowling, National Archives, representing Society of Motion Picture Engineers; V. B. Sease, du Pont Film Manufacturing Company; F. W. Willard, National Research Council; and H. M. Lydenberg, New York Public Library, chairman. The Film Preservation Committee of the Society of Motion Picture Engineers has been helpful also.

${ }_{2}$ Research Associate at the National Bureau of Standards, representing the National Research Council.

* By John G. Bradley, Chief, Division of Motion Pictures and Sound Recordings, The National Archives, Washington, D. C. 
cational purposes. The interest in films for such purposes has become widespread because of the great saving in library space and the greater availability of material afforded the research worker.

At the request of the American Library Association and other organizations concerned with the preservation of important records, an investigation of the chemical and physical properties of cellulose acetate films, relative to their stability, was undertaken. This work is a natural extension of the studies previously made on the preservation of records on paper. The American Library Association is interested in the stability of cellulose acetate film and information concerning the best practice with respect to its storage and use. The National Archives is interested in all problems involved in the preservation and use of both nitrate and acetate films because both types will be stored and used there. By coordinating the two projects, more rapid progress has been obtained than would have been otherwise possible.

\section{MOTION-PICTURE FILMS STUDIED}

A motion-picture film comprises a base of transparent sheeting, usually approximately 0.0055 inch in thickness, coated with an emulsion in the form of a thin layer of gelatin containing a silver compound extremely sensitive to the action of light. There are two types of film base in use, both being transparent cellulose esters: cellulose nitrate and cellulose acetate.

Cellulose nitrate sheeting is the base in the ordinary theater type of motion-picture film. It is essentially a mixture of cellulose nitrate and camphor, and is highly combustible. It ignites at low temperature and burns very rapidly, giving off large volumes of oxides of nitrogen which are poisonous. Cellulose nitrate is relatively unstable in any form. The base of the safety type of film contains cellulose acetate. This material is comparatively stable chemically, is not highly inflammable, and burns no more rapidly than ordinary paper. The samples used in this study were furnished by the three principal domestic manufacturers of motion-picture films and were said to be representative of current commercial products.

\section{DESCRIPTION OF TESTS}

The stability of the films was studied by determining the changes in their properties under accelerated aging. Various aging treatments were tried, consisting in: oven-aging at $100^{\circ} \mathrm{C}$ in dry air, a method of aging that had been found suitable for paper; ${ }^{3,4}$ oven-aging with moisture provided by an open vessel of water in the oven; heating in a steam chest at $99^{\circ} \mathrm{C}$; and oven-aging at $100^{\circ} \mathrm{C}$ with the film inside stoppered bottles containing saturated potassium sulphate solut on, providing a relative humidity of 95 percent.

Both physical and chemical tests were used to measure the effects of accelerated aging. Any change in chemical properties should be reflected in the physical properties, and it is desirable to obtain a correlation between them. The physical property most sensitive to deterioration appears to be the flexibility, which can be measured by a folding test. The loss in weight on heating was also recorded. The

3 BS J. Research 3, 476 (1929) RP107.

+ Paper Trade J. 95, 28 (July 1932). 
chemical testing comprised determinations for: acetyl content, and copper number on acetate film; flash or explosion temperature, and stability at $134.5^{\circ} \mathrm{C}$ for nitrate film; and acidity as $\mathrm{pH}$, and relative viscosity of acetone solutions for both types of film.

The determination of acety] content, undertaken to find whether the aging of acetate film resulted in loss of acetic acid, was discarded for the more direct determination of free acidity, developed in the film, as change in $\mathrm{pH}$. The available methods of testing for acetyl content were not sufficiently sensitive to detect changes due to aging. Likewise, for nitrate film, the flash-point test was found to be unsatisfactory as a measure of stability, and the stability test at $134.5^{\circ} \mathrm{C}$ used by the Ordnance Department of the United States Army for testing guncottons was substituted. This latter test was found to be applicable to the testing of nitrate film as the time of reaction was affected

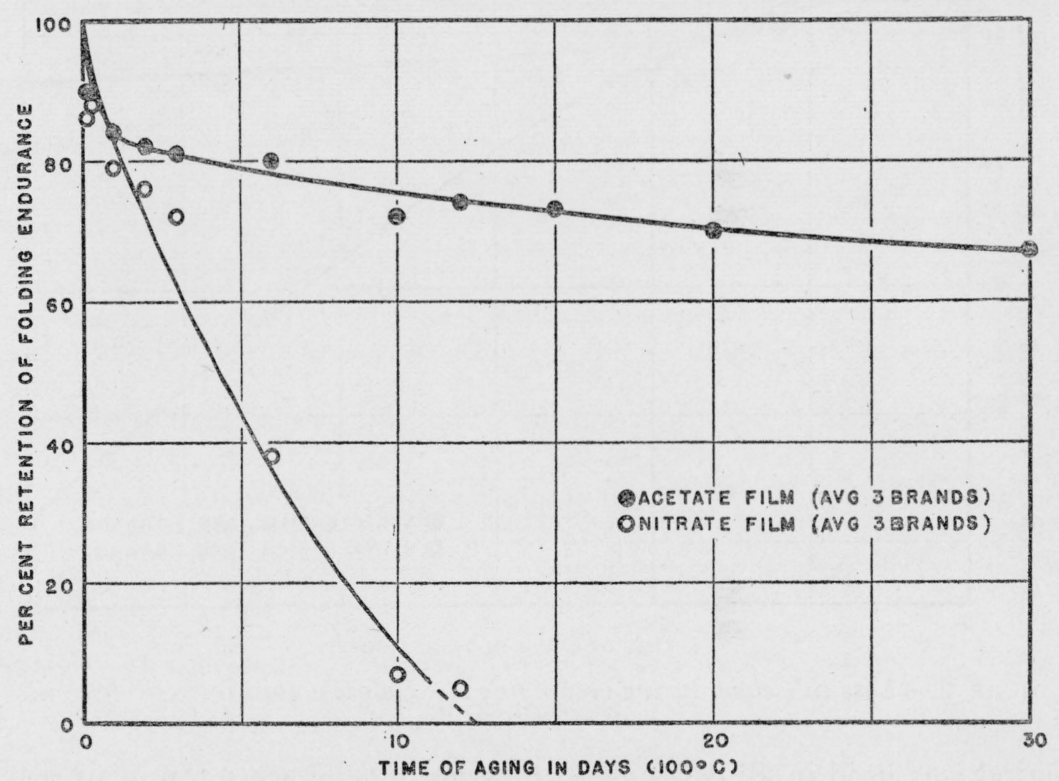

FIGURE 1.-Effect of oven-aging on flexibility of cellulose acetate and cellulose nitrate motion-picture films.

sharply both by changes due to artificial aging, and by those due to natural aging. All aging tests were made on samples of whole film, that is, film with the emulsion. Samples were taken from new films that had been exposed and processed by the manufacturers. These films gave a negative test for residual hypo.

\section{PHYSICAL PROPERTIES}

\section{FOLDING ENDURANCE}

In studying the effect of accelerated aging on the folding endurance, two types of folding testers were tried; the MIT folding tester used for paper and the Pfund type of tester which is used by the Du Pont Film Manufacturing Corporation for films. The Pfund type was found to be somewhat more reliable as to reproducibility of results than the MIT type. Difficulty was encountered in the use of the latter 
because a slight distortion of the film on aging caused edge cracks when it was folded over the jaw edges. The Pfund type folds without tension, forming a small loop not in contact with any metal edge. It appears to give a satisfactory measure of flexibility and, although handoperated, the results are quite reproducible.

For measurements of folding endurance, test strips of film were cut $15 \mathrm{~mm}$ wide and about $75 \mathrm{~mm}$ long and aged at constant temperature for the required length of time. After aging, the strips were conditioned under the standard conditions of 65 -percent relative humidity and $70^{\circ} \mathrm{F}$ before testing. Control strips were in all instances conditioned and tested under the same conditions. A 24-hour conditioning

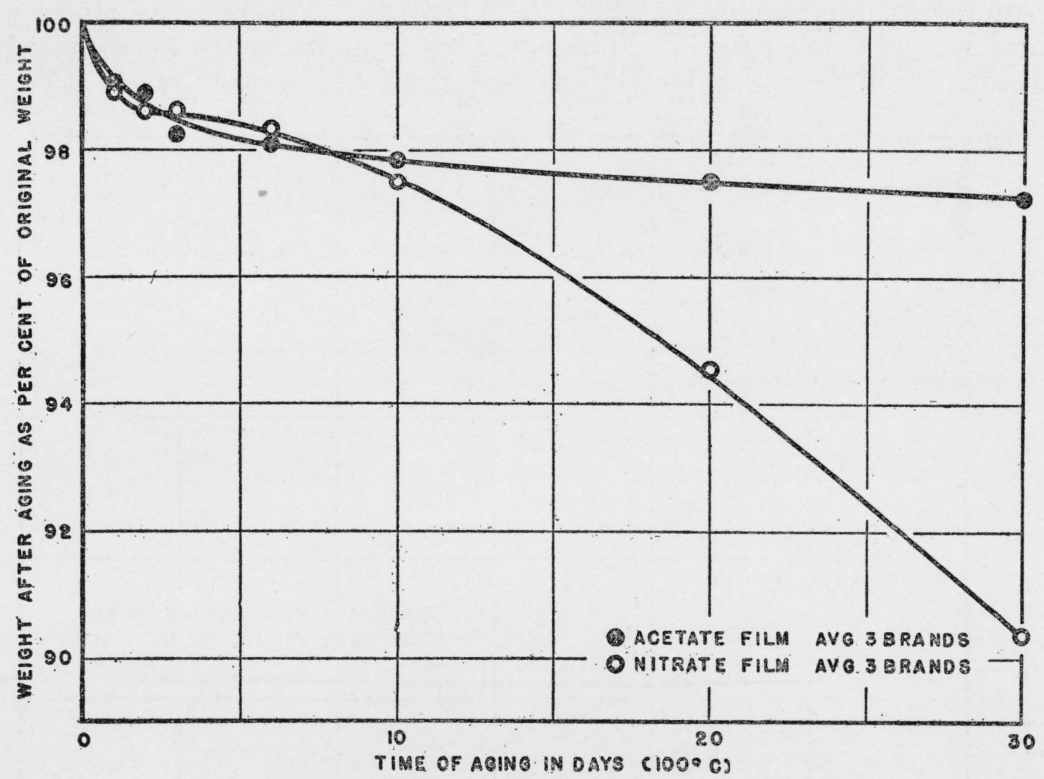

FIGURE 2.-Loss in weight during oven-aging of cellulose acetate and cellulose nitrate motion-picture films.

period was used in all cases as both types of films were found to reach practically constant weight within that time.

The results of ordinary oven-aging at $100 \pm 2^{\circ} \mathrm{C}$ on the folding endurance of cellulose acetate and cellulose nitrate film are shown in figure 1. The curves show average values for three brands each of acetate film and nitrate film. Both curves start with about the same slope and show a retention of between 80 and 85 percent of the original folding endurance after 24 hours' aging. On continued heating, the acetate film changed very slowly in folding endurance. After 30 days the average retention was about 67 percent, and after 150 days (not shown on curve) it was still about 50 percent of the original value. For the nitrate films, the loss in folding endurance continued at about the initial rate until all folding endurance was lost. After 10 days' heating, the folding endurance was zero for 2 brands and the third became zero after a few days of additional heating. 
Moisture vapor in the oven practically doubled the loss in folding endurance for both types of film for a 72 -hour period. It was not continued for longer periods because using open vessels of water in the oven resulted in extreme and uncontrollable changes in relative humidity. In the steam chest, nitrate film went to pieces rapidly, while in the case of the acetate the base became opaque and separated from the emulsion without loss of folding endurance. Upon heating this base in the oven, it again became transparent. The most consistent results with respect to effects on folding endurance were obtained with oven-aging in dry air.

\section{LOSS IN WEIGHT}

Oven-aging of film was found to be accompanied by a loss in weight that was not regained on reconditioning. This fact aids in understanding some of the results of oven-aging on folding endurance.

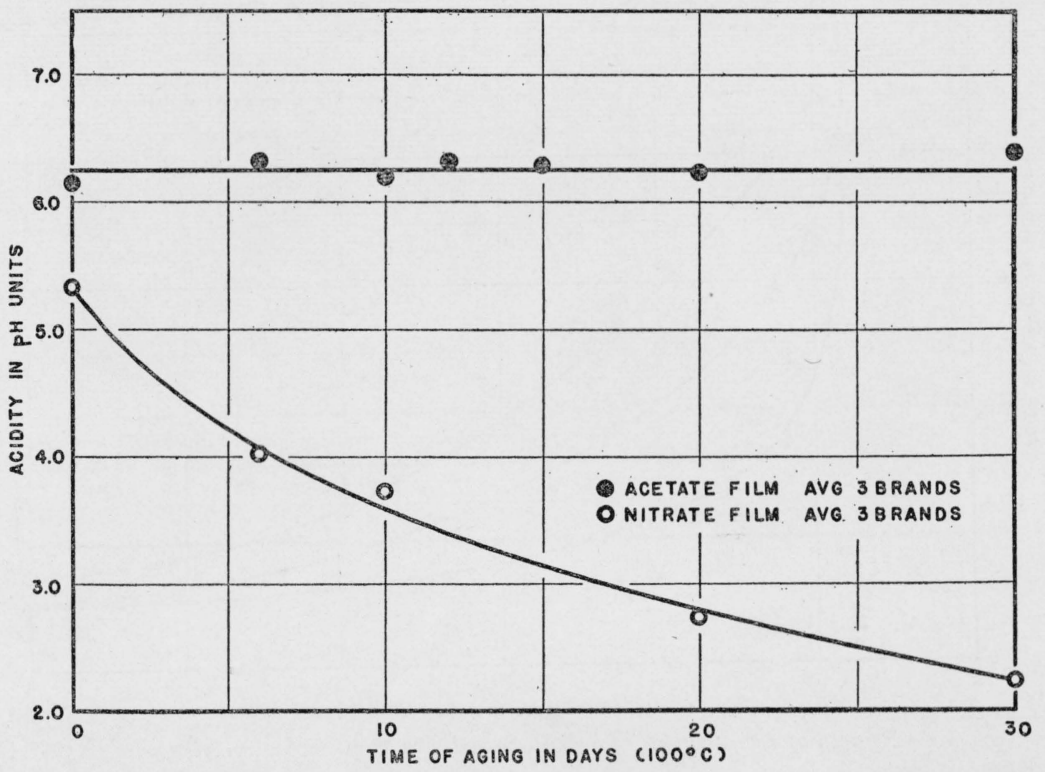

FIgURE 3.-Effects of oven-aging on $\mathrm{pH}$ of cellulose acetate and cellulose nitrate motion-picture films.

Weighed samples of film were aged for different periods and weighed again after conditioning for 24 hours. The final weights calculated as percentages of the original weights are shown on the curves in figure 2. The curves are similar for both types of film up to a period of about 6 days, but thereafter the loss in weight of acetate film is slight, while the nitrate continues to lose at a comparatively rapid and constant rate. These curves are similar in several respects to those for folding endurance. In each instance, the initial change was probably due to the loss of volatile substances, such as residual solvents and camphor in the case of nitrate film. On further aging, the slow change in the acetate film indicates greater stability. 


\section{CHEMICAL PROPERTIES}

\section{1. $\operatorname{ACIDITY}(\mathrm{pH})$}

Decomposition of cellulosic materials is usually accompanied by an increase in their acidity; hence measurements of $\mathrm{pH}$ were made to determine whether aging was accompanied by any increase in acidity. For this test, 1-g samples of film were weighed and after aging the base of the specimen was dissolved in $100 \mathrm{ml}$ of acetone containing 10 percent by volume of water. ${ }^{5}$ The $\mathrm{pH}$ of the solution was measured with a glass electrode. The results are shown in figure 3 , in which the $\mathrm{pH}$ of the solution is plotted against the time of aging. The curve for acetate film shows some fluctuations, but no significant changes for any period of aging up to 30 days. On the other hand, the nitrate films showed a regular drop in $\mathrm{pH}$ from an average value

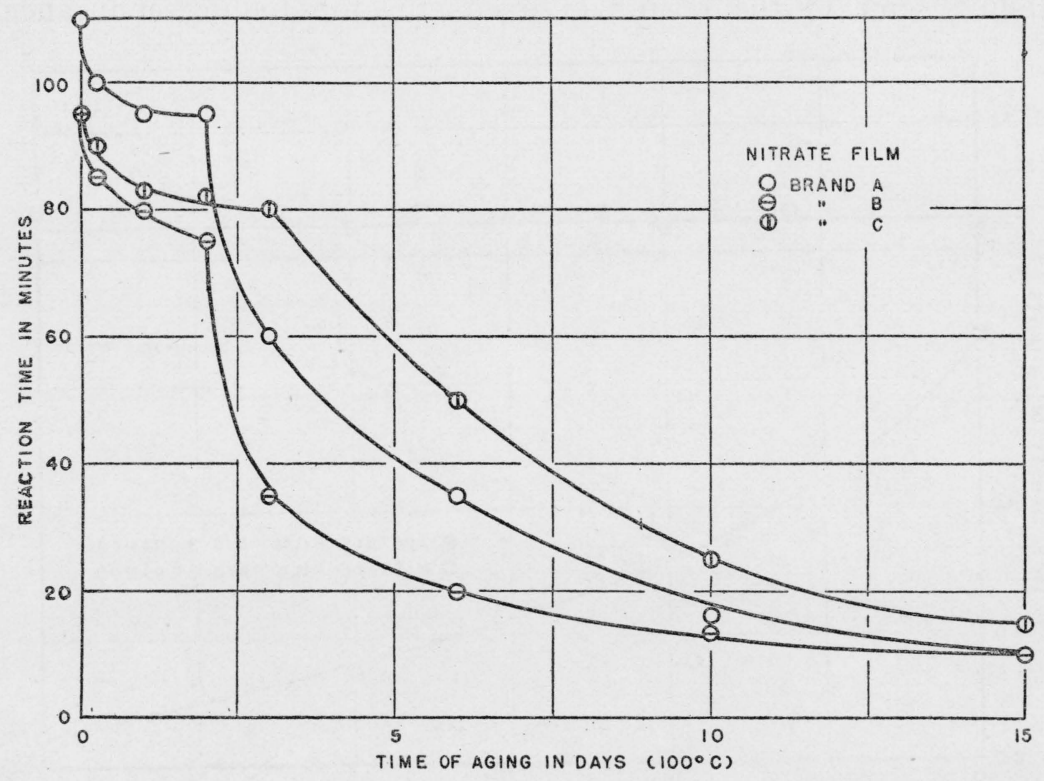

FIGURE 4.-Effects of oven-aging of cellulose nitrate film on its stability at $134.5^{\circ} \mathbf{C}$.

of about 5.3 for new film to 2.3 after 30 days of aging. Correspondingly high acidity was found also in every test of old nitrate film that was visibly deteriorated as a result of natural aging.

\section{STABILITY TEST OF NITRATE FILM}

The stability test at $134.5^{\circ} \mathrm{C},{ }^{6}$ used for testing pyrocellulose and guncotton, was found to be applicable to cellulose nitrate film. In this test, a 1-g specimen is placed in a closed tube with normal methyl violet paper inserted in the tube to about $2.5 \mathrm{~cm}$ above the test specimen. The time required at a constant temperature of $134.5^{\circ} \mathrm{C}$ for the gases given off from the specimen to change completely the color of the paper to salmon pink is observed. The effects of oven-aging

\footnotetext{
${ }_{5}$ T. K. Brownson and F. McCray, The electrical conductivities of hydrochloric acid and potassium chloride in water and acetone-water mixtures. J. Chem. Soc. 127, 2923 (1925).

- U. S. Army Specification no. 50-14-3.
} 
on the stability of nitrate film, as determined by this test, are shown in figure 4. The curves for the different commercial brands are alike in general characteristics, showing slow rates of change of stability for the first two days of heating, then sharp breaks in the curves followed by much more rapid loss of stability. Old film, visibly deteriorated by natural aging, usually had a reaction time corresponding to 10 to 15 days of oven-aging.

\section{COPPER NUMBER}

Some forms of degraded cellulose reduce copper from an alkaline solution of copper sulphate, and the amount reduced is considered a measure of the amount of such material present. In applying this

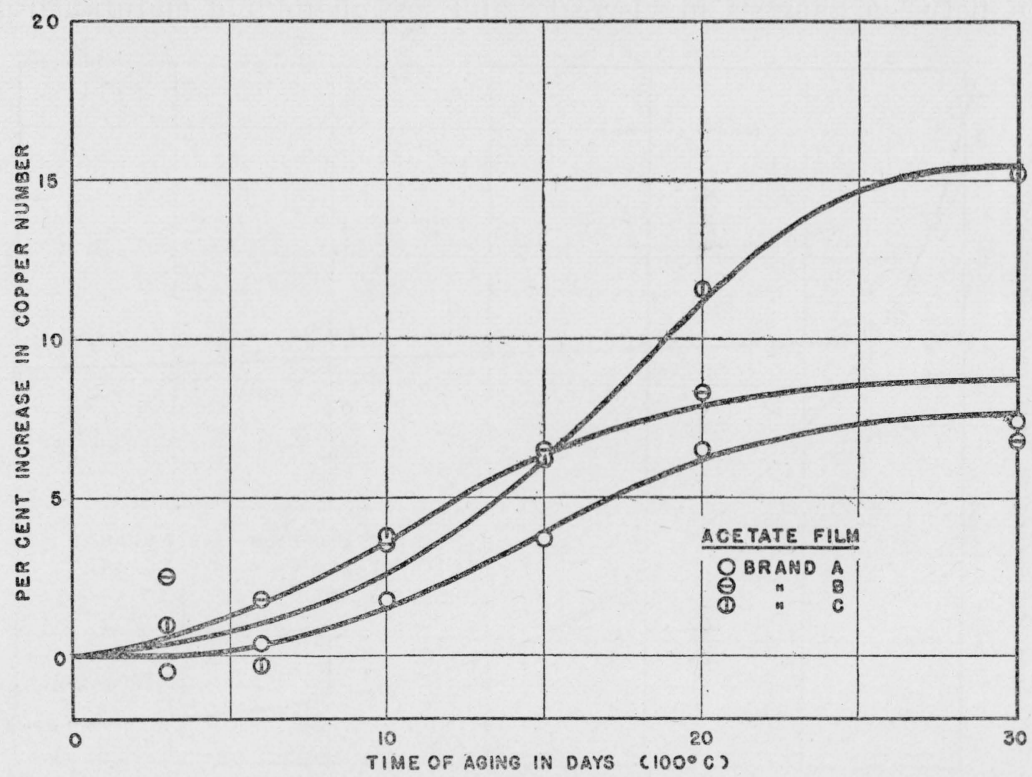

FigURe 5.-Effect of oven-aging on the copper number of cellulose acetate motionpicture film.

test to films, the standard method ${ }^{7}$ for testing the copper number of paper was used, except that the samples were prepared in the following manner. The film was dissolved in acetone, and the cellulose ester precipitated in hot water, washed, and dried. The resultant samples were in soft fluffy form comparable to the paper samples prepared by grinding. Both acetate and nitrate films were tried, but no figures were obtained for nitrate film because it dissolved completely in the alkaline copper sulphate solution.

The data on the copper numbers of three brands of acetate film are shown in figure 5. Four series were run on each brand. The reproducibility of results was not very good but, in each instance, there was an increase in copper number with aging. For 30 days of aging, the increases in copper number values were 7,15 , and 7 percent, respectively, an average of about 10 percent. Compared with the change

\footnotetext{
${ }_{7}$ TAPPI Standard T430m, Tech. Assn. of the Pulp and Paper Ind.
} 
occurring in stable papers, this would be considered a small increase, indicative of relatively high chemical stability. The initial copper number values for the three brands of film averaged 3.2, which is considerably higher than for permanent paper. This is not surprising when the more drastic chemical treatment used in making the acetate film is considered. Hence, the two materials are not comparable on the basis of actual values, but rather on the rate of change on heating.

\section{VISCOSITY}

The relative viscosity of acetone solutions of the film base was found to be the most sensitive and reliable chemical test for following the deteriorative effects of aging on both acetate and nitrate films. The viscosity data are of special interest because of the excellent correlation between changes in viscosity and loss in folding endurance on

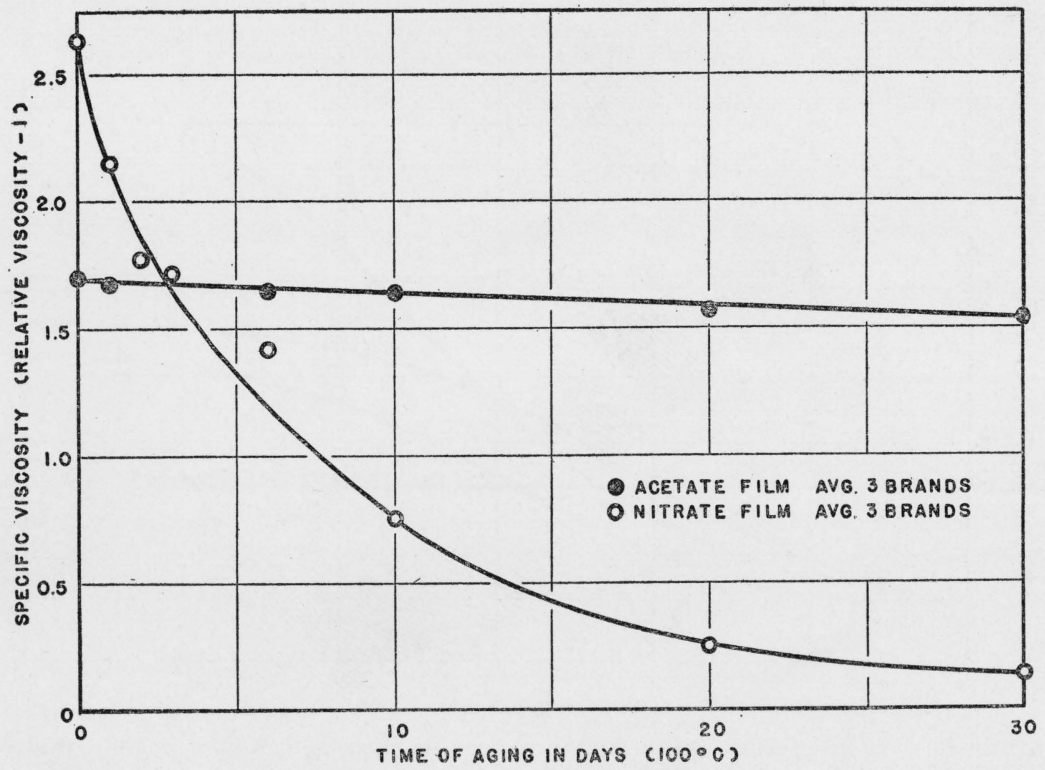

FIgURE 6.-Effect of oven-aging on the viscosity of cellulose acetate and cellulose nitrate motion-picture films.

aging. This good correlation between changes in physical and chemical properties indicates a sound basis for judging relative stability.

The molecular weight of substances with long-chain molecules is related to the viscosity of their dilute solutions, according to Staudinger, ${ }^{8}$ by the following equation:

$$
\eta_{r}-1=\eta_{s p}=K_{m} \cdot c \cdot M
$$

where $\eta_{r}$ is the relative viscosity, which is the ratio of the viscosity of the solution to the viscosity of the solvent; $\eta_{s p}$ is the specific viscosity as defined by Staudinger; $K_{m}$ is a constant, $c$ is the concentration in primary moles per liter of solution; and $M$ is the molecular weight. From this equation it can be seen that for equally concentrated solu-

\footnotetext{
${ }^{8}$ H. Staudinger, Die Hochmolekularen Organischen Verbindungen (Berlin, 1932).
} 
tions of the same $K_{m}$, the viscosity depends only on the molecular weight. Consequently, any break down in the molecular structure should result in a lowering of the viscosity.

The effect of accelerated aging on viscosity was determined by viscosity measurements before aging and after various aging periods. Specimens weighing $1.000 \mathrm{~g}$ each were used. The test was made by dissolving the film base away from the emulsion in acetone, making the solution up to $100 \mathrm{ml}$ in a volumetric flask, and measuring the time of flow of the solution in an Ostwald viscosity pipette immersed in a constant-temperature water bath at $30 \pm .02^{\circ} \mathrm{C}$. The product of the time of flow and density of the solution divided by the corresponding product for the solvent gives the relative viscosity.

The results of ordinary oven-aging in dry air are shown in figure 6 . This shows specific viscosity plotted against time of aging. The

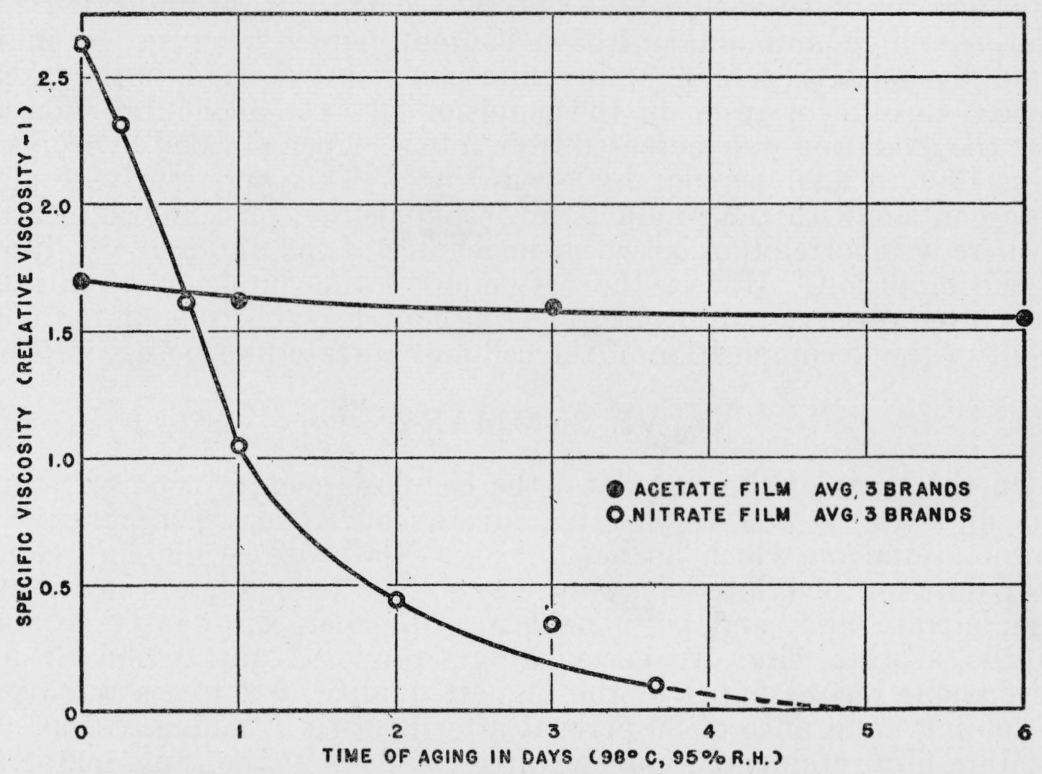

FIGURE 7.-Effect of oven-aging with high relative humidity on viscosity of cellulose acetate and cellulose nitrate motion-picture films

curve for acetate film shows very slow change. The decrease in specific viscosity for 30 days' aging was only from 1.70 to 1.54 , or 9.4 percent. For the same time of aging, the nitrate film decreased from an average value of 2.63 to 0.14 , which indicates a complete change in structure. Old nitrate film badly deteriorated from natural aging gave a viscosity corresponding to about 10 days of oven-aging.

In order to determine the effect of high humidity, samples of film were aged suspended over a saturated solution of potassium sulphate in a closed bottle. The temperature maintained in the bottle was $98 \pm 2^{\circ} \mathrm{C}$, and at this temperature the relative humidity is 95 percent. The results are shown graphically in figure 7 . Under these conditions, decomposition was more rapid for both types of film, but especially for the nitrate film. The high relative humidity resulted in hydrolysis with the formation of nitric acid, which greatly accelerated the reaction. The average time required for a 95-percent 
decrease in viscosity was about 3 days, compared with 30 days for oven-aging in dry air. The decrease in viscosity of acetate film for 3 days of aging was 6.5 percent. This is a greater change than that for the same time of aging in a dry atmosphere (fig. 6) but is small compared with the change found for nitrate film, and indicates excellent stability even under these extreme conditions.

\section{EFFECTS OF AGING ON GELATIN EMULSION}

Ordinary oven-aging in dry air had no effect on the gelatin emulsion of acetate films as far as could be observed. The aging at $100^{\circ} \mathrm{C}$ with 95-percent relative humidity resulted in some softening of the emulsion and a tendency of the emulsion to separate from the base. The first visible evidence of deterioration of nitrate film with natural aging is a discoloration and softening of the emulsion. Tests of the emulsions from such films showed that oxidation, as indicated by relatively high ammonia nitrogen content, and hydrolysis, as indicated by relatively high amino nitrogen content, had both taken place. Results of tests on the emulsion of oven-aged film showed that the oxidation was increased from 0 to 0.89 percent and hydrolysis from 1.89 to 3.90 percent by oven-aging. This apparently results from contact with the products of decomposition of cellulose nitrate as there was correlation between the acidity of the film and condition of the emulsion. Hence, the softening of the emulsion of nitrate films often observed after natural aging may be said to be an indirect result of the decomposition of the cellulose nitrate film base.

\section{SUMMARY}

On the basis of the test data, the cellulose acetate type of safety film appears to be a very stable substance. It is a comparatively new material on which no natural aging data are available. However, data on the relative resistance to accelerated aging of the acetate film, nitrate film, and permanent record papers are very favorable to the acetate film. A specification, proposed by Scribner, ${ }^{9}$ for permanent record paper of the highest quality, requires a retention of folding endurance of 85 percent after heating 72 hours at $100^{\circ} \mathrm{C}$. Acetate film retained 50 percent after 150 days at the same temperature. Nitrate film, known to be relatively impermanent, had no folding endurance after 10 days of heating.

The relatively high chemical stability of acetate film is shown by the fact that aged samples showed no increase in acidity, whereas nitrate film became distinctly acid. For permanent record paper, the copper number must not be greater than 1.0 nor increase more than 0.5 when heated for 72 hours. The average value of the copper number of cellulose acetate was 3.2. This is higher than for permanent record paper as would be expected as a result of the chemical treatment undergone in acetylation of the cellulose, but on heating for 72 hours at $100^{\circ} \mathrm{C}$ cellulose acetate showed an average increase of less than 0.5 .

The best evidence of the high stability of acetate film is furnished by results of viscosity measurements. When heated for 72 hours at $100^{\circ} \mathrm{C}$, the specific viscosity decreased about 2 percent, and after 30

\footnotetext{
$\because$ Trans. Am. Soc. Mech. Engrs. 52, [PI] 21 (August 1930).
} 
days of aging only 9 percent. With nitrate film, the decrease was 35 percent in 72 hours and 95 percent after 30 days of aging.

While it is not possible to predict the life of acetate film from these results, the data show that the chemical stability of the film, with respect to oven-aging, is greater than that of papers of maximum purity for permanent records. On the basis of this comparison, cellulose acetate motion-picture film appears to be very promising for permanent records.

Acknowledgments are made to J. E. Gibson and Meyer Reiss, Research Associates, for assistance in this investigation while assigned to this Bureau by the Division of Motion Pictures and Sound Recordings, National Archives.

Washington, September 22, 1936. 